\title{
The Contribution of Lower Limbs Explosive Power on Snatch Lift Techniques at HBT Sasana
}

\author{
H Syampurma
}

\author{
Faculty of Sports Sciences, Universitas Negeri Padang,Prof. Dr.Hamka, Padang, Indonesia \\ *Corresponding author. Email: hilmainursyam@yahoo.com
}

\begin{abstract}
The purpose of this study was to observe the contribution of lower limbs explosive power to on snatch lift technique in Sasana HBT Padang. The type of research was correlational research design. The sample of this research comprised of 15 athletes of weight lifting at Sasana HBT Padang. The instruments used in this research were vertical jump test and snatch force technique. Data were analyzed with Pearsons Product Moment. Based on data analysis,it was found that lower limbs muscle strength had significant relation with snatch lift technique, with rh $(0,616)>\mathrm{rt}(0,514)$ with contribution equal to $31,80 \%$.
\end{abstract}

\section{Keywords: Limbs explosive, snatch lift techniques}

\section{INTRODUCTION}

The government is currently actively implementing development programs, including the field of weightlifting. For the first time weightlifting was competed in the West Sumatra province sports week in 2010. We can see West Sumatra weightlifters competing in the XII PROPROV (West Sumatra province sports week) event in West Sumatra. All of their achievements came from gladiator SASANA and Padang city HBT which is one of the Sasanas under the supervision of PENGCAB PABBSI Padang city. At present weightlifting is gaining serious attention because weightlifting achievements are already global.

The implementation of these activities aims to educate athletes towards improving the quality of life that better, upholds the values of sportsmanship, discipline, and can foster national unity. In the RI Law No.3 of 2005 concerning the National Sports System (2007: 1) mentioned:

"National sports aims to maintain and improve physical health and fitness, the achievement of the quality of human life, instill moral values and noble character, sportsmanship, discipline and foster national unity to strengthen national defense, and lift the dignity of the nation".

Talking about sports achievements is something that is not easy. Achievements will be realized if there is good cooperation between the government, the community, sports people, and the elements that support high achievement, with the development of weightlifting and the development of each district since the XII PROPROV (West Sumatra province sports week) race in SUMBAR (West Sumatera), there are many gains from a weightlifting branch, and it really helps rank achievements in an area. The development of achievements can be carried out by starting with the junior and senior regional championships and adolescents each year in order to regenerate and breed athletes to be developed to a higher level of competition so that West Sumatra can be respected at the national level.

In weightlifting, there are two types of techniques that are assessed, such as Snatch and Clean And Jerk. Snatch technique is very important in weightlifting, so certain conditions are needed as capital in weightlifting such as having adequate physical conditions in the form of strength. As Fox said in Arsil (2008: 43) strength is the power or pressure of a muscle, or more precisely is a muscle group that can be used against an energetic resistance in a maximum effort/effort.

Strength is very important for weightlifting, especially the Snatch technique for contracting in order to arouse passion because it is the driving force of physical activity in the sport but basically leg muscle strength in HBT Sasana is not perfect because the force is still weak in holding the leg muscles. While the ability of a person in carrying out the force quickly and strongly is very large role in carrying out explosions of muscle contraction in the maximum force as explained by Corbin in Arsil (1990: 71) explosive power is the ability to display or to exert power explosively or quickly.

It is suspected HBT Sasana athletes have a Snatch technique that is still weak and inefficient. Weak and inefficient Snatch techniques of Weightlifting HBT Sasana Padang athletes are caused due to the ability of the explosive ability of leg muscles that are still low and not maximal. The low explosive power of the ability of the leg muscles to perform fast and powerful repulsion is not good at the same time. As a result, what was expected about explosive power never reached a perfect point for the type of Snatch force at the HBT 
Sasana Padang. If the ability of leg muscle strength cannot lift and hold force for a long time, the type of Snatch force will fail and the force results will not reach the perfect stage.

Then the determinants of weightlifting sports achievement include aspects of biology consisting of: 1 . Potential or basic abilities of the body which include strength, speed, muscle explosive power, working power of the heart and lungs, flexibility, coordination and time. 2. Functions of organs that include the working power of the heart. 3. Body structure and posture that includes body shape. 4 . Nutrition in the needs of athletes.

While for weightlifters who practice at HBT Sasana Padang, their achievements are not brilliant at the national level because of that they are prepared to the XII PROPROV in SUMBAR, there are various factors that cause poor performance are lack of discipline of athletes in training programmed by the coach, consequently he Snatch force technique that is expected to not be achieved optimally in the end the results of the Snatch force failed in the match.

Result ability of Snatch force is still weak and low, like 3 hours of training every da,y only 1 hour that is run well and lack of mentality greatly affects a person's soul in the competition as a result Snatch force results are less developed, and less professional body shape for weightlifters. As a result, the championship that followed was always inferior to other weightlifting athletes in other regions.

Based on this fact, researcher is interested in conducting research on the factors of physical conditions that require the ability of Snatch forces in weightlifting, especially related to the contribution of limb muscle strength to the results of the Snatch force. Weightlifting is a sport that relies on the speed of coordination, flexibility, time, both hands that play weightlifting in the spirit of full motivation and instinct in lifting heavy material. Budi in Agusta (1997: 19), states that: weightlifting is lifting material from iron and is a stimulating and tense exercise. In England, this sport is called Weightlifting, and the athlete is called a lifter.

In the weightlifting branch known 2 types of forces, namely Snatch and Clean \& Jerk. Each force is given 3 times the opportunity, in each class. Lifter was given 3 times the chance to lift iron according to his ability. The second batch can be added $5 \mathrm{Kg}$ again, the third batch is added $2.5 \mathrm{Kg}$ again and so on.

Legitimate forces obtain a value, for the perfect force the referee will issue a white flag for the legitimate force, while the red flag for the illegitimate force, the referee will amount to three people. If the force has been carried out, then it is summed and obtain what is called the Total Lift for each type of force. In the picture below is a method of holding iron handlebar for each type of force.
Snatch is two hands holding a barbell as wide as 80 $100 \mathrm{~cm}$, then pulled quickly, the iron docked to the body and performs reflections under the stomach, then the iron is immediately lifted above the head in one direct motion. This movement together with body movements in a squat position and hands support the barbell in a straight state.

According to Sinatra Kaises (1991), the way to do a snatch is with a barbell handlebar located horizontally in front of the legs of the lifter, the handlebar held in one motion from the bottom (platform) up until the arms are straight above the head, while the legs are in motion split "(both legs divide or squat. The barbell that has been lifted must be held in its final position without moving, the arms and legs are straightened until the referee gives a signal to lower the iron onto the platform.

From the squatting position, the body changes to a standing position with the hands still straight supporting the barbell above the head perfectly. Bob Hoffman described the snatch very succinctly when he said that the object was to pull high, low and fix the weight above the head. Bob Hoffman in Bil Watson (1975: 72), said that: standing as an object with a full force and body down by holding heavy loads perfectly.

After the referee gave the signal, the lifter lowered the barbell. Usually the referee uses white and red flags to determine whether the force is legitimate or not. We can see a lifter carrying out a snatch force in a heavyweight position trying to stand up to achieve the perfect type of force.

The explosive power of the leg muscles is a very decisive component in snatch style weight lifting capabilities. Lifter who has good limb muscle strength, when carrying out heavy load snatch is appointed a direct lifter. While the iron goes straight up to the lifter to sit to get a balance in the reflection below the abdomen, and it is an advantage for him. In addition, to get the results of a clean force to do speed when lifting iron, it requires the strength of the arm muscles. So it can be said that there is a significant relationship between leg muscle strength to weightlifting ability of snatch style.

\section{METHOD}

The type of this research was correlational research. The research was conducted at Sasana Padang HBT (Himpunan Bersatu Teguh) street Klenteng No.311. The population of this study was weightlifting athletes at Padang HBT Association (Himpunan Bersatu Teguh), which numbered 15 people. Sampling technique using total sampling.

The research instrument for data collection was carried out tests on vertical jumps to measure the explosive power of leg muscles. To measure the results of the snatch force technique, a snatch test was carried out by 
giving three times the chance to lift the maximum load. Data analysis used percentages with product moment correlation formula.

\section{RESULTS AND DISCUSSION}

In weightlifting, the ability to pull and hold loads was strongly influenced by leg muscle strength to produce maximum and perfect strength. According to Aderai (2006: 69) said "the body part that has the most muscle and the largest compared to other body parts (has a percentage of 50\%) from the area of all the muscles of the front body".

From the above opinion it was clear that the explosive power of the leg muscles was a very decisive component in the snatch force's technical abilities. Lifter who had good limb muscle explosive power, when carrying out a heavy load snatch lifts the lifters directly while the iron went straight up to the lifter to sit to get the balance reflected below the abdomen and it was an advantage for him. In addition, to get clean batch results speed when lifting iron really required the explosive power of the leg muscles.

From the results of the analysis that had been obtained, it can be concluded that there is a significant relationship between the explosive power of leg muscles with the snatch force technique at Sasana Padang HBT. The contribution which was given by the explosive power of limb muscles on the results of the snatch force technique at Padang HBT were $31.80 \%$, while $68.20 \%$ were influenced by other factors. The explosive power of the leg muscles was the ability of one's limb muscles to use the maximum strength that was deployed in the shortest time an athlete has, of course, it would be better if they did not ignore the factors that could influence the results of the snatch force technique, such as at identification of the problem.

\section{CONCLUSIONS}

Based on the results of the research that the reseacher has described in the previous chapter, it can be concluded that there is a significant relationship between the explosive power of the leg muscles against the snatch force technique of athletes at Sasana Padang HBT where $0.546>\mathrm{r}_{\text {tabel }} 0.514$ at $\alpha=0,05$. With a contribution of $31.80 \%$

\section{REFERENCES}

[1] Aderai. (2006). Healthy lifestyle Fitness and Bodybuilding. Publisher. BALL Tabloid.

[2] Arsil. (2008). Fostering Physical Conditions. Padang: FIK.

[3] ------ (1990). Fostering Physical Conditions. Padang: FIK
[4] BIIL WATSON.1975. TRACKLE WEIGHTLIFTING. London

[5] Budi. (2006). Profile of Strength of Long-Term Training Athletes in Central Java Sports Weightlifting, Weightlifting and Body Building PON XVII from 2005 - 2006. FIKUNS.

[6] Republic of Indonesia Ministry of Youth and Sports. No. 3. (2005). About the National Sports System. Jakarta: President of the Republic of Indonesia.

[7] Sinatra Kaeses. (1991). Weightlifting Technique Regulations.

[8] Sudjana. (2005). Statistical Method. Bandung: Transito. 